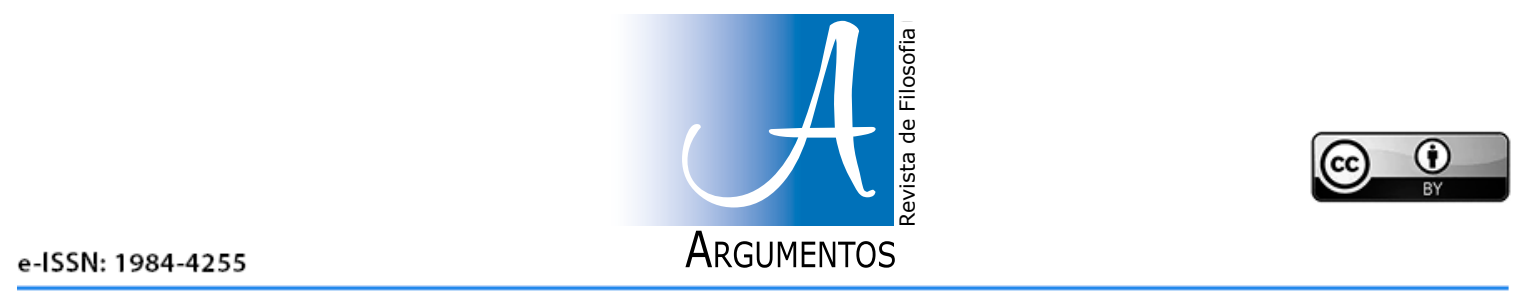

D01: $10.36517 /$ Argumentos.25.23

RESENHAS

\title{
MARGUTTI, Paulo. História da filosofia do Brasil. A ruptura iluminista (1808-1843). São Paulo: Loyola, 2020, 712 p.
}

\author{
Judikael Castelo Branco \\ https://orcid.org/0000-0002-4551-2531 - E-mail: judikael79@hotmail.com
}

Poucas palavras são menos afeitas a genitivos do que o termo "filosofia". Qualquer autor que pretenda simplesmente falar dela tomando-a numa relação que apresente um sentido limitativo se encontra com a tarefa incontornável de justificar as próprias ambições diante de um número não indiferente de críticas - muitas delas bastante consistentes. No entanto, uma rápida revisão bibliográfica mostra que essas mesmas críticas não atingem da mesma forma àqueles que falam de filosofia alemã, francesa ou norte-americana e os que tratam de filosofia brasileira.

Quem desafia essas críticas e se aventura nas pesquisas sobre o tema, particularmente no que tange à história da filosofia brasileira, terá de se posicionar diante do quadro formado pelas duas perspectivas alternativas que dominam os debates desde o século XIX. Em uma dessas perspectivas, encontramos não apenas a afirmação de que houve filosofia no Brasil nos diferentes períodos da nossa história, como também a de que ela se desenvolveu com certas relações de influência causal e de conexão lógica. Esse primeiro ponto de vista é aquele em que se colocam, por exemplo, as leituras de Miguel Reale e de Antônio Paim. Do outro lado, porém, encontramos aqueles que negam a existência de uma tal filosofia e ao máximo concedem o fato de que houve manifestações esporádicas de arremedos de sistemas europeus, na maioria das vezes mal copiados e mal adaptados a partir de manuais pouco significativos. Entre esses últimos, temos os trabalhos de Silvio Romero, Leonel Franca, Lima Vaz e mais recentemente Ivan Domingues. Cada uma dessas formas de abordagem originou uma tradição específica na historiografia da filosofia brasileira, de tal modo que os adeptos de uma ignoram o que se passa na outra. No entanto, segundo a interpretação de Paulo Marguti (2020a, p. 676-685), com a qual concordamos, ambas compartilham de equívocos fundamentais, a saber, em primeiro lugar, elas não confrontam adequadamente os textos relevantes; depois, elas ressaltam a autoimagem negativa que tendemos a produzir de nós mesmos, e, por último, fazem uma leitura excessivamente ideológica dos textos dos pensadores brasileiros. 
É justamente por causa da sua insatisfação com esse "contexto culturalmente 'esquizofrênico'"' (MARGUTTI, 2013, p. 10) que Paulo Margutti Pinto propõe uma nova apresentação da história da nossa filosofia nacional. ${ }^{1}$ O primeiro resultado de fôlego da sua empreitada veio a público em 2013, pelas Edições Loyola, a "História da filosofia do Brasil. O período colonial (1500-1822)".

Agora, depois de um lapso de seis anos, chega-nos finalmente o segundo volume da obra, no qual o autor insere o subtítulo "A ruptura iluminista (1808-1843)". Trata-se, portanto, do período correspondente à "superação da matriz colonial" (MARGUTTI, 2013, p. 351). Para o pensamento brasileiro, essa superação representou o abandono de certas características do catolicismo barroco, e se caracterizou, sobretudo, pela concentração em textos especificamente filosóficos, de um lado, e, de outro, pela adoção de uma postura mais aberta às novas perspectivas científicas, no terreno teórico, e para as ideias liberais, no domínio político. Há de se dizer ainda que esse ambiente de "ideias mais arejadas" é também consequência da ação política de Marquês de Pombal.

A simples comparação das datas escolhidas como os marcos limítrofes dos dois tomos torna patente a complexidade das relações entre eles. Em uma palavra, não se trata de mera continuidade, antes o autor agora retoma, reinterpreta e reelabora a última parte do primeiro volume, consagrada precisamente à ruptura iluminista, e que, na obra de 2013, estava concentrada entre anos de 1808 e 1822. No novo volume, Margutti estende o período dessa ruptura até 1843 (ano em que Antônio Pedro de Figueiredo traduziu o Curso de História da filosofia, de Victor Cousin), repassando os nomes de Silvestre Pinheiro Ferreira (a quem dedica agora 150 páginas, enquanto em 2013, havia tratado do autor das Preleções em apenas 18 laudas), Frei Caneca e Hipólito da Costa. O elenco dos pensadores estudados é por si só uma marca da originalidade da perspectiva que se procura. A lista completa, além dos três já referidos, traz ainda os nomes de Diogo Feijó, Monte Alverne, Nísia Floresta, Marquês de Maricá e Miranda Rego. Em outros termos, aos pensadores já normalmente presentes em outras abordagens da história da filosofia brasileira, somam-se autores até agora pouco considerados, como Frei Caneca e Nísia Floresta. Porém, merece especial destaque a inclusão de Miranda Rego, escritor até aqui completamente ignorado pelos historiados da filosofia do Brasil, embora muito importante para a história da nossa literatura nacional.

O método continua sendo a combinação do rastreamento histórico das ideias dos filósofos tratados com a confrontação dessas mesmas ideias com a realidade, ou seja, usando os termos tomados de Victor Goldschmidt, um arranjo entre o método lógico e o método genético (MARGUTTI, 2013, p. 34). A busca dessa conciliação repousa na ideia de que a ênfase no método histórico em detrimento do lógico ocasionou, por exemplo, a autoimagem negativa presente em leituras como a de Cruz Costa. Margutti se esforça, em última instância, para manter sempre nítida a relação entre os problemas, as perspectivas e seus contextos.

No que concerne à interpretação das obras expostas, o caminho segue sendo a passagem da hermenêutica diatópica (Raimundo Panikkar) à hermenêutica pluritópica (Madina Tlostanova e Walter Mignolo) (MARGUTTI, 2013, p. 37), na qual se procura a superação das dificuldades de compreensão do que está fora de determinado horizonte de significados. O que está em jogo, finalmente, é o reconhecimento da alteridade da filosofia brasileira, o que, para Margutti continua comprometido pela contaminação de uma imagem negativa subordinada a critérios europeus.

O autor inicia o texto justificando o hiato temporal entre os dois volumes, ao mesmo tempo em que entrega ao leitor as razões que movimentam as 700 páginas do novo trabalho.

\footnotetext{
1 Sobre o significado de "filosofia nacional" para o autor, remetemos ao seu artigo O que é filosofia brasileira? (MARGUTTI, 2020b).
} 
Em primeiro lugar, confessa a própria ambição de dar um tratamento o mais completo possível para cada autor em particular e para o período considerado como um todo. Em segundo lugar, reconhece o aperfeiçoamento da própria pesquisa no que diz respeito à coleta e à organização dos dados (MARGUTTI, 2020a, p. 9). O resultado imediato é o imenso volume de informações que dá corpo ao livro. ${ }^{2}$ No entanto, o mais importante é que os dois fatores apontados levam o autor a nos oferecer não uma, mas duas histórias, a saber, uma história da filosofia do Brasil, e uma história da história da filosofia do Brasil.

Para a história da filosofia do Brasil de Margutti, também valem as observações feitas no início da nossa apreciação: o autor deve justificar o próprio esforço de relatar os caminhos e os percalços da filosofia não apenas presente em nossas terras, mas presente de uma forma peculiar, justamente por estar aqui, refletir a nossa história e lidar com as questões que nos interessam ou que deveriam nos interessar. Logo, a resposta à questão da possiblidade de uma filosofia brasileira deve certamente se ligar aos problemas concernentes à história de nossa própria formação cultural, social e política. No entanto, ainda mais fundamental para qualquer esboço de resposta é a determinação do que cf.se entende propriamente por filosofia. Em uma palavra, tratamos aqui de um problema metafilosófico. A solução de Margutti é buscar na noção de "visão de mundo", articulada por Wilhelm Dilthey, uma forma de compreensão específica da natureza e da tarefa da filosofia que lhe permita falar propriamente de filosofia brasileira. Se essa noção já estava presente no primeiro volume (MARGUTTI, 2013, p. 323), é só na "Introdução" do segundo que o autor desenvolve suficientemente o que ele mesmo entende por "visão de mundo", concordando com Dilthey ao defini-la como "um construto hermenêutico que fornece o significado do mundo" (MARGUTTI, 2020a, p. 26), mas procurando a cada passo escoimar esse conceito de alguns de seus compromissos metafísicos e etnocêntricos (MARGUTTI, 2020a, p. 32). Vista dessa forma, não apenas existe uma história da filosofia do Brasil, mas ela é um exercício fundamental para o conhecimento dos nossos esforços na articulação de nossa própria "visão de mundo". Para a ruptura lluminista, as conclusões de Margutti apontam para uma visão de mundo que se articula fundamentalmente a partir de três problemas predominantes: a conciliação entre empirismo e racionalismo; as questões em torno do melhor regime de governo para o Brasil no momento da sua Independência; e, por fim, a conciliação das doutrinas filosóficas com a crença religiosa, mais precisamente com o catolicismo. Se por um lado as questões epistemológicas refletem o que se fazia na filosofia europeia, por outro lado, os outros problemas são exigências específicas do nosso contexto social e político, o que, na ótica do autor, sustenta a ideia de uma filosofia propriamente brasileira no período estudado.

No que respeita ao que chamamos de "história da história da filosofia do Brasil", a obra de Margutti revisita os trabalhos daqueles que também têm procurado compreender os passos da construção do pensamento brasileiro. O autor trilha então um caminho raro na comunidade filosófica nacional ao dialogar de forma honesta e crítica com outros escritores. Talvez os melhores exemplos sejam as constantes evocações de Antônio Paim (na apresentação de Silvestre Pinheiro Ferreira e Frei Caneca) e de Silvio Romero (ao tratar de Monte Alverne e de Marquês de Maricá). Também para fins de ilustração, recordamos a observação de Margutti para os limites da distinção de Antônio Cândido entre "manifestações literárias" e "Iiteratura" quando aplicada à filosofia. Nesse caso, o autor se opõe aos resultados obtidos por

\footnotetext{
${ }^{2}$ A abordagem de Margutti resultou, como ele mesmo reconhece (2020a, p. 23), em exposições muito longas, em alguns casos, as seções ficaram tão extensas "que poderiam se transformar em pequenos livros". Isso efetivamente aconteceu com a publicação das pesquisas sobre Nísia Floresta (MARGUTTI, 2019).
} 
Ivan Domingues, mesmo se o tratamento completo da questão só será trazido na terceira parte da obra (MARGUTTI, 2020a, p. 634-635).

Há de se dizer também, e a nosso ver trata-se de um ponto importantíssimo, que a revisão que ele faz da nossa historiografia filosófica alcança a sua própria pesquisa, o que de certa forma antecipamos quando tratamos da relação entre os dois tomos. $O$ autor reconhece a necessidade de retomar os resultados da sua interpretação sobre a filosofia brasileira no período colonial à luz dos trabalhos recentes de Lúcio Álvaro Marques (2015; 2018). Essa atitude pode ser percebida ainda em questões pontuais, como no caso de adequações terminológicas. É o que vemos, por exemplo, quando Margutti substitui a expressão "empirismo católico" - usada no primeiro volume para corrigir a noção tradicional de "empirismo mitigado" (MARGUTTI, 2013, p. 156) - por "empirismo espiritualista" (MARGUTTI, 2020a, p. 123). Para ele, a razão da mudança pode ser posta nesses termos: "a expressão empirismo católico reconhece que estamos diante de uma forma atenuada de empirismo, mas, além de indicar precariamente a dimensão racionalista, enfatiza em excesso o lado católico dessa solução" (MARGUTTI, 2020a, p. 123).

Considerando que o próprio autor promete uma segunda edição revista e ampliada do seu primeiro volume (MARGUTTI, 2020a, p. 18), temos nas mãos uma obra em construção, mas cujos méritos já se anunciam irrecusáveis e movidos pela consciência de seu autor de se tratar de uma referência que nasce como leitura obrigatória para os interessados no tema.

A nosso ver, há alguns elementos que poderiam ser observados. Em primeiro lugar, ainda que seja um recurso para poupar o leitor da busca de certas informações, as páginas dedicadas a Locke e a outros filósofos estrangeiros conhecidos correm o riso de se colocarem como excursos inseridos no corpo do texto. É uma impressão possível, por exemplo, diante da discussão acerca do "sistema Leibniz-Wolf" (MARGUTTI, 2020a, p. 132-134). Em segundo lugar, o livro ganharia muito com uma contextualização histórica mais robusta. Sobre esse ponto, salta à vista a desproporção de apenas 7 páginas dedicadas aos "Fatos históricos relevantes para a filosofia brasileira no período" (que voltam resumidas no balanço final). Nessas poucas páginas, com efeito, o autor apresenta apenas de forma genérica os efeitos da transição da corte portuguesa para o Brasil e da criação das Escolas de Cirurgia de Salvador e do Rio de Janeiro bem como das Faculdades de Direito de São Paulo e de Recife (para logo descartar estas últimas e reservá-las para um devido tratamento no futuro). Por fim, ainda que não seja um costume das nossas casas editoriais brasileiras, a História da filosofia do Brasil, de Paulo Margutti, quer pela riqueza da pesquisa quer pelas proporções que está assumindo, demanda que se pense na anexação de um índice onomástico para as próximas edições.

\section{Referências}

MARGUTTI, P. História da filosofia do Brasil. A ruptura iluminista (1808 - 1843). São Paulo: Loyola, 2020a.

MARGUTTI, P. "O que é filosofia brasileira?". In: CARDOSO, D.; MARGUTTI, P. (Orgs.). II Colóquio Pensadores Brasileiros. Porto Alegre: Editora Fi, 2020b. p. 115-139.

MARGUTTI, P. Nísia Floresta, uma brasileira desconhecida. Feminismo, positivismo e outras tendências. Porto Alegre: Editora Fi, 2019.

MARGUTTI, P. História da filosofia do Brasil. O período colonial (1500 - 1822). São Paulo: Loyola, 2013. MARQUES, L. A lógica da necessidade. O ensino de Rodrigues Homem no Colégio do Maranhão (1720-1725). Porto Alegre: Editora Fi, 2018. 
MARQUES, L. Philosophie Brasiliensis. História, conhecimento e metafísica no período colonial. Porto Alegre: Editora Fi, 2015.

\section{Sobre o autor}

Judikael Castelo Branco

Professor da Universidade Federal do Tocantins (UFT). Doutor em Filosofia pela Universidade Federal do Ceará (UFC) e pela Université Charles de Gaulle (Lille).

Recebido em: 04/08/2020.

Received: 04/08/2020.

Aprovado em: 05/10/2020.

Approved: 05/10/2020. 